\title{
FORMAR-SE E SER FORMADOR: ROTAS FORMATIVAS MUSICAIS DE RELIGIOSOS NO CONTEXTO CATÓLICO BRASILEIRO
}

\author{
"Self-formation" and the "formation": \\ formative musical paths for religious in the \\ Brazilian Catholic context
}

\author{
Formarse y ser formador: caminos formativos \\ musicales de religiosos en el contexto \\ católico brasileño
}

\author{
Michelle Arype Girardi Lorenzetti \\ Universidade Federal do Rio Grande do Sul \\ michelleglorenzetti@gmail.com
}

\begin{abstract}
Resumo: Este artigo refere-se a uma parte da tese de doutorado (Lorenzetti, 2019) cujo objetivo foi compreender as rotas formativas de religiosos católicos, colaborando para o entendimento de processos de formação musical ocorridos, na Igreja Católica brasileira, após o Concílio Vaticano II (19621965). O foco da pesquisa dirigiu-se para o formar-se e o formar a outros, tendo como participantes quatro religiosos. O estudo enquadra-se na área de sociologia da educação musical com apoio teórico da sociologia da vida cotidiana (Pais, 1993, 2003). Para conduzir esta pesquisa, optou-se por uma abordagem qualitativa, utilizando o estudo de caso coletivo (Stake, 1999), no qual, através de entrevistas, o caso instrumental (Stake, 1999) em que cada religioso se configurou contribuiu para a compreensão da formação musical. A formação musical nesse contexto pode ser compreendida como significante de uma prática pedagógica não "formalizada", porém plena de escolhas pedagógicas e apresentando certa sistematização.
\end{abstract}

Palavras-chave: Formação musical. Sociologia da educação musical. Igreja Católica.

\begin{abstract}
This article refers to a part of a doctoral dissertation (Lorenzetti, 2019) whose objective was to throw light on the formative paths of Brazilian catholic religious, collaborating to understand the processes of musical formation that took place in the Brazilian Catholic Church after the Second Vatican Council (1962-1965). The focus is on the "self-formation" and the "formation" of others by four religious. The study is framed within the area of the sociology of music education with the theoretical support of the sociology of everyday life (Pais, 1993, 2003). In order to conduct this research, a qualitative approach was chosen and a collective case study approach (Stake, 1999) was used in which, through interviews, the instrumental case (Stake, 1999) in which each religious was characterized contributed to the understanding of their musical formation. Musical formation in this context can be understood as a signifier of a pedagogical practice that is not "formalized", but full of pedagogical choices and presenting a certain systematization.
\end{abstract}

Keywords: Musical formation. Sociology of music education. Catholic Church.

Resumen: Este artículo forma parte de la tesis de doctorado (Lorenzetti, 2019) cuyo objetivo fue comprender los caminos formativos de religiosos católicos, ayudando a la comprensión de los procesos de formación musical ocurridos en la Iglesia Católica brasileña, después del Concilio Vaticano II (19621965). El tema de la investigación se enfocó en el formarse y el formar a otros teniendo como participantes a cuatro religiosos. El estudio se encuadra en el área de la sociología de la educación musical con el apoyo teórico de la sociología de la vida cotidiana (País, 1993, 2003). Para llevar a cabo esta investigación, se optó por un enfoque cualitativo utilizando el estudio de caso colectivo (Stake, 1999), en el cual, a través de entrevistas, cada religioso se configuró como un caso instrumental (Stake, 1999) lo que contribuyó para la comprensión de la formación musical. La formación musical en este contexto puede ser comprendida como significativa de una práctica pedagógica no "formalizada", sin embargo, plena de elecciones pedagógicas y presentando cierta sistematización.

Palabras clave: Formación musical. Sociología de la educación musical. Iglesia Católica. 


\section{INTRODUÇÃO}

O presente artigo origina-se da tese de doutorado Formar-se e ser formador: rotas formativas musicais de religiosos no contexto católico brasileiro na perspectiva da sociologia da educação musical e da vida cotidiana (Lorenzetti, 2019). ${ }^{1}$

A temática da tese insere-se em uma discussão sobre a multiplicidade de espaços onde se aprende e se ensina música (Souza, 2007), sendo o contexto religioso um desses espaços. É uma pesquisa, na área de educação musical, que estuda, a partir de uma perspectiva sociológica, um contexto religioso católico, com o foco no como se aprende e se ensina música, no formar-se e formar a outras pessoas. Os aportes teóricos da sociologia da educação musical (Souza, 1996, 2000, 2014) e da sociologia da vida cotidiana (Pais, 1993, 2003) embasaram o estudo dos processos de formação musical que ocorrem no contexto católico.

A pesquisa visou compreender as rotas formativas de quatro religiosos católicos, colaborando para o entendimento de processos de formação musical que ocorreram na Igreja Católica no Brasil após o Concílio Vaticano II. O Concílio Vaticano II ocorreu entre 1962 e 1965, sendo uma conferência ecumênica que gerou profundas mudanças na Igreja. Entre as modificações, o rito da missa passou a ser celebrado no vernáculo, ou seja, no Brasil, em português. Em consequência, a música precisou ser adaptada e repensada, gerando a necessidade de um intenso trabalho formativo para que um novo repertório fosse constituído e houvesse pessoas capacitadas para exercer as funções musicais na liturgia.

O foco do trabalho dirigiu-se para o formar-se e o formar a outros dos religiosos: Padre José Henrique Weber, Irmã Míria Therezinha Kolling, Padre Ney Brasil Pereira e Irmã Custódia Maria Cardoso. Os colaboradores da pesquisa foram escolhidos por terem um importante papel na formação musical na Igreja Católica brasileira. Inicialmente não era intenção buscar somente colaboradores religiosos (freiras ou padres), porém isso acabou ocorrendo tanto devido ao papel deles na formação pós-conciliar como por sua longa trajetória em cursos que eles ofereciam. Busquei formadores com extensa experiência, que estivessem atuando em cursos, palestras, oficinas de música ou na condução de ensaios. O conhecimento prévio desse campo permitiu-me recordar alguns nomes, os quais foram sendo confirmados em consultas à internet, leitura de livros e conversas com pessoas do meio litúrgico-musical. O convite que recebi em 2015 para começar a participar do Encontro de Compositores ${ }^{2}$

\footnotetext{
1 A tese foi defendida em 2019 no Programa de Pós-Graduação em Música da Universidade Federal do Rio Grande do Sul sob orientação da Dra. Jusamara Souza.

2 O Encontro de Compositores é organizado pela Equipe de Reflexão de Música Litúrgica, com apoio da Comissão Episcopal da Pastoral da CNBB. Desde 2006 são promovidos encontros anuais para formação litúrgico-musical de compositores. Para participar desse encontro é necessário receber um convite da equipe de reflexão (Fonseca, 2009).
} 
da Conferência Nacional dos Bispos do Brasil (CNBB) permitiu-me uma aproximação mais estreita com os referenciais da música litúrgica do Brasil.

Dois livros colaboraram na listagem inicial dos possiveis participantes da pesquisa: Música brasileira na liturgia II, organizado por Molinari (2009), e A música litúrgica no Brasil 50 anos depois do Concílio Vaticano II, de Fonseca e Weber (2015). Inicialmente foram listados dez nomes das regiões Sul e Sudeste do Brasil, pois havia sido feita uma delimitação geográfica em função dos custos de deslocamento para a realização das entrevistas presenciais. Dois critérios foram estabelecidos para a definição dos colaboradores: estarem atuando na formação musical e terem a formação voltada para a prática litúrgico-musical. Este último critério foi reforçado pelos conhecimentos adquiridos com a revisão da literatura e pelos primeiros contatos com os colaboradores. O contato para a pesquisa foi feito com os quatro colaboradores e todos concordaram em participar.

"Formar-se" aqui é entendido como os processos nos quais os conhecimentos e habilidades musicais vão sendo adquiridos ao longo dos anos pelos indivíduos. A compreensão do formar-se neste trabalho não se esgota nas questões técnicas adquiridas, expandindo-se para as relações que se estabelecem entre as pessoas e a música e o aprofundar da compreensão da experiência musical (Kertz-Welzel, 2017, p. 110). ${ }^{3}$ Neste trabalho, soma-se a isso a relação com a instituição religiosa. O termo alemão Bildung, que poderia ser entendido por formação e aproxima-se do conceito de formar-se da tese, é utilizado por autores da educação musical no âmbito internacional (Johansen, 2010; Kertz-Welzel, 2017).

Já por "formar a outros" consideram-se os processos nos quais conhecimentos e experiências são compartilhados. Ao falar dos processos de transmissão musical no ambiente da Igreja Católica, é comum o uso da palavra "formação", e, referindo-se à pessoa que transmite, "formador" ou "assessor". Formar, nesse contexto litúrgico-musical, implica preocupar-se não somente com conteúdos musicais, mas também com a vivência cristã e as experiências celebrativas. Para referir-me aos percursos de formação dos religiosos e seus caminhos na formação de outras pessoas, adotei o conceito de "rotas formativas" na perspectiva do cotidiano (Pais, 2003).

O Brasil possui grande diversidade de grupos religiosos. Os dados do Censo Demográfico de 2010 (cf. Instituto Brasileiro de Geografia e Estatística, 2012) revelam tanto essa diversidade ${ }^{4}$ como, em comparação com pesquisas anteriores, a diminuição de pessoas que se declaram católicas. Apesar disso, ao responder o questionamento “Qual a sua religião ou culto?”, 64,6\% de pessoas se disseram católicas.

\footnotetext{
3 "Bildung is determined by the relationship between people and music [...]. Bildung in music means to deepen the understanding and experiencing of music. It means improving musical skills, learning how to responsibly use music, and how to enrich one's life through music" (Kaiser, 1998 apud Kertz-Welzel 2017, p. 110).

4 Segundo Mafra (2013, p. 15), no Censo de 2000 foram coletados "mais de 15 mil nomes de religiões de pertencimento" que foram classificados em 144 categorias; no Censo de 2010 as religiões foram organizadas em 66 categorias.
} 
Segundo Teixeira (2005, p. 16), "o catolicismo no Brasil revela uma grande complexidade". Coexistem diferentes visões teológicas, o que impacta o modo de viver a fé, a compreensão do papel da música nesse contexto e as escolhas formativas: para quem ensinar, como e por que fazê-lo. Na pesquisa optou-se pelo foco em um tipo de música: a música litúrgica, olhando, a partir desse foco, para as ações formativas visando às celebrações e não aos shows e eventos. Segundo Almeida (2014, p. 10), "o conceito de música litúrgica pertence ao contexto da reforma litúrgica desencadeada pelo Concílio Ecumênico Vaticano II (1962-1965) no âmbito do catolicismo". Pode-se conceituar "música das liturgias cristãs" ou "música ritual dos cristãos" como "as práticas vocais e instrumentais integradas nas liturgias cristãs" (Universa Laus, 2008, p. 78).

\section{REVISÃO DE LITERATURA}

Pela revisão de literatura realizada, observou-se que o interesse pelo tema emerge, muitas vezes, da própria experiência dos pesquisadores com a música na Igreja Católica, sendo a maioria dos trabalhos divulgados a partir de 2011 (Cattelan, 2012; Dias, 2017; Jefremovas, 2017; Lorenzetti, 2012, 2015; Louro; Reck; Oliveira; Zacarias, 2011; Nogueira, 2012).

Experiências diversas vividas no cenário da Igreja Católica são abordadas por Louro, Reck, Oliveira e Zacarias (2011) em seus relatos. As atividades no ministério de música são consideradas como um "laboratório de aprendizagem musical" no qual há a possibilidade de a aprendizagem ocorrer na prática e ao vivo (Louro; Reck; Oliveira; Zacarias, 2011, p. 218). Os autores revelam que, no ambiente religioso, tiveram que lidar com: a transposição de tonalidade, repertório inesperado, fazer música sem a leitura de partitura, improviso musical e tocar de ouvido.

As monografias de Nogueira (2012), Cattelan (2012), Dias (2017), Jefremovas (2017) e a dissertação de Oliveira Neto (2017) emergem de suas experiências com música na Igreja Católica. A prática musical em grupo, através de oficinas de canto, na Diocese de Anápolis, em Goiás, despertou o interesse de Nogueira (2012). Cattelan (2012), apoiado em diários de aula, problematiza experiências na Igreja Católica, considerando a missa como contexto de aprendizagem, devido às improvisações requeridas do músico. Dias (2017) investigou experiências de aprendizagem de grupo de cantores e instrumentistas da Paróquia São Judas Tadeu, em São Paulo. Jefremovas (2017) analisa experiências de ensino de piano de dois professores no contexto da Igreja Católica de Canoas, localizada no Rio Grande do Sul. Através de entrevistas, a autora obteve informações sobre a formação musical; o início da atuação dos professores; o perfil dos alunos, segundo os docentes; as escolhas didáticas, dentre outros aspectos.

Há ainda diversos trabalhos que abordam a partir da educação musical outros contextos religiosos. Nos congressos de educação musical realizados no Brasil pela Associação Brasileira de Educação Musical (Abem), um dos primeiros trabalhos a retratar a aprendizagem musical no ambiente religioso foi o de autoria de Santos e Figueiredo (2003). Eles apresentam a realidade 
de elaboração de um projeto político-pedagógico do Curso de Bacharel em Música Sacra (Rio de Janeiro) do Seminário Teológico Batista do Sul do Brasil, o qual prepara profissionais para atuarem em igrejas, escolas de música livres e espaços comunitários. Segundo os autores, o curso supre as igrejas evangélicas por possibilitar "pessoas habilitadas ao exercício das funções de regência congregacional e coral; da técnica vocal [...]; pianista acompanhador [...], organista; e do educador musical para as escolas de música internas" (Santos; Figueiredo, 2003, p. 724).

O artigo de Torres (2004) tornou-se um marco na produção sobre educação musical e religião, por mostrar a presença da religiosidade nas lembranças musicais e por ser o primeiro a abordar isso explicitamente na Revista da Abem. Torres (2004, p. 64), em um recorte de sua tese de doutorado, apresenta e discute algumas questões sobre "as lembranças de música e os entrelaçamentos com as práticas religiosas: primeira comunhão, grupos de jovens, missas, encontros de casais e cultos".

A pesquisa realizada (Lorenzetti, 2019) soma-se a esse conjunto de estudos, ampliando a compreensão do contexto religioso católico. O trabalho, com apoio no material empírico, possibilitou acessar memórias que não são contadas em livros, revelando a complexidade das rotas formativas nesse ambiente religioso.

\section{REFERENCIAL TEÓRICO-METODOLÓGICO}

A sociologia da vida cotidiana (Pais, 1993, 2003) e a sociologia da educação musical (Souza, 1996, 2000, 2014) embasaram teoricamente a pesquisa. Segundo Souza (2000, p. 28), o cotidiano pode ser visto como

um lugar social de processos, crenças, de achar sentido comunicativo e interativo, nos quais os participantes da sociedade constroem suas identidades sociais e em cujas molduras se estabelece um entendimento sobre as normas sociais, realizam-se interações sociais e se reconhecem processos intersubjetivos como sua parte essencial.

Ainda segundo Souza (2000, p. 28), na construção de uma teoria da educação musical, apoiada nessa perspectiva, vários aspectos adquirem relevância. Um deles é o fato de essa perspectiva comprometer-se com "a análise individual histórica, com o sujeito imerso, envolvido num complexo de relações presentes, numa realidade histórica prenhe de significações culturais" (Souza, 2000, p. 28). Assim, mostra-se de interesse do investigador recuperar "a pluralidade de possiveis vivências e interpretações" (Souza, 2000, p. 28), o que se relacionaria com a ideia de Pais (2003, p. 30), na qual a vida cotidiana é o "tecido de maneiras de ser e de estar", sendo importantes as "maneiras de fazer".

Para conduzir esta pesquisa, optou-se por uma abordagem qualitativa, utilizando o estudo de caso coletivo (Stake, 1999). O estudo de caso foi assumido como "o estudo da particularidade e complexidade de um caso singu- 
lar para conseguir entender sua atividade em circunstâncias importantes" (Stake, 1999, p. 11, tradução minha). ${ }^{5}$ Através da técnica de entrevistas individuais semiestruturadas, foi feito o estudo de quatro casos particulares, no que se configura um estudo instrumental de casos (Stake, 1999). Os colaboradores concordaram em utilizar seus nomes reais, e não pseudônimos, bem como concordaram com o registro das entrevistas em áudio e vídeo. Para a pesquisa somente os áudios foram transcritos e utilizados. Os colaboradores tiveram acesso às transcrições e concordaram com sua utilização. Em diversos momentos eles manifestavam sua alegria pela participação na pesquisa e pela possibilidade de registrar suas memórias. Durante o trabalho de coleta de dados, dois entrevistados faleceram, mas isso não impediu que seu material fosse utilizado, já que a autorização havia sido concedida.

Uma das técnicas utilizadas foi o diário de pesquisa, no qual foram registradas experiências acadêmicas e reflexões diversas que colaboraram na escrita da tese. Assim como esses registros e as entrevistas, fotografias e outros artefatos, em grande parte cedidas pelos próprios colaboradores para a pesquisa, levaram a novos questionamentos, possibilitando novas respostas. Foram cedidas 24 fotografias digitalizadas, 18 fotografias reimpressas, cinco LPs, seis fitas em VHS gravadas em DVDs, seis CDs, 15 apostilas encadernadas com partituras e alguns textos soltos e cópias de cartas digitadas em máquina de escrever.

A atenção pelos pequenos detalhes ao longo da pesquisa foi compreendida como um "paradigma epistemológico" (Burke, 2017, p. 53). Alguns exemplos disso seriam: as imagens disponibilizadas e os gestos dos colaboradores durantes as gravações. Essa ideia de Burke (2017) aproxima-se da compreensão de Pais (2003, p. 46), na qual "a atenção pelos detalhes da vida cotidiana" ocorre a partir da "recusa ou impossibilidade de ver a totalidade".

\section{ROTAS FORMATIVAS DE QUATRO RELIGIOSOS}

$\mathrm{Na}$ abordagem da formação musical dos quatro religiosos, foram ouvidas histórias envolvendo música, infância, escola, família, mídia, Igreja, formação acadêmica, professores particulares, estudo no exterior. As histórias formativas foram tecidas em meio a suas atuações como formadores.

Lançar o olhar sobre a música na Igreja e ter acesso às rememorações dos religiosos permitiu distinguir alternativas da apropriação do conhecimento musical e das escolhas que os formaram. Na pesquisa foi aparecendo, para além de seu objetivo, o interesse dos colaboradores de conservar o que foi narrado, ter suas histórias e memórias compartilhadas, trocar experiências. Ao focar a investigação nos relatos de quatro religiosos, estes foram compreendidos como sujeitos que vivem/viveram a música, porém sem perder o olhar sobre o modo como o pensamento institucional religioso manifestava-se em suas escolhas e falas. Os processos de formação musical dos colaborado-

\footnotetext{
5 No original: "El estudio de casos es el estudio de la particularidad y de la complejidad de un caso singular, para llegar a comprender su actividad en circunstancias importantes."
} 
res não poderiam ser isolados de suas experiências religiosas, pois a religião não era simples parcela de suas vidas, mas um elemento que os configurava, os movia e moldava seu jeito de ensinar música, como apresento a seguir. A apresentação revela um pouco da história de cada religioso nessa perspectiva de formar-se e ser formador.

\section{Padre José Henrique Weber}

Padre José Henrique Weber teve seus primeiros contatos com a música através de seu pai, Samuel, que cantava na igreja. Ele recorda: "E quando chegava em casa, durante a semana, à noitinha, ele [pai] ensinava toda a família os cantos lá da igreja. Cantava e a gente aprendia com ele" (Lorenzetti, 2019, p. 86).

Seu pai, que sonhara ser padre, o incentivou a ingressar no seminário. Padre Weber, ao entrar na Congregação Verbo Divino, continuou tendo experiência com música. Foi lá que teve suas primeiras aulas de harmônio, chegando, posteriormente, a ser, no Seminário Maior, o encarregado da banda. Lá também se envolveu com o coro.

De 1959 a 1967, Padre Weber esteve em Roma aprimorando seus estudos musicais. Residia no Colégio do Verbo Divino durante a realização do Concílio Vaticano II. Ali ele acompanhou o que acontecia pelos jornais e pelos bispos de sua congregação que moravam no mesmo local, os quais, quando retornavam à noite, contavam o que estava ocorrendo.

Quando Padre Weber concluiu seus estudos, a CNBB, através do Cônego Amaro Cavalcanti, solicitou seu retorno ao Brasil, principalmente devido à sua formação em música. Padre Weber assumiu um papel formativo através de escritos; da publicação de documentos sobre a música litúrgica; dos cursos; de assessorias e palestras; da participação em ensaios; de composições e arranjos; de reflexões compartilhadas, de LPs e CDs gravados.

Como assessor da CNBB, em 1967, estabeleceu-se na cidade do Rio de Janeiro, local da sede da Conferência até 1977. Permaneceu como assessor da CNBB até 1983, tendo viajado a diversas capitais para ministrar cursos. Padre Weber tem se dedicado ao registro de suas memórias sobre a música litúrgica, composição e arranjos para coros.

\section{Irmã Míria Therezinha Kolling}

Desde os 7 anos, Irmã Míria Therezinha Kolling, que nasceu no interior de Dois Irmãos, no Rio Grande do Sul, queria ser religiosa. No colégio onde estudou, conheceu as Irmãs do Imaculado Coração de Maria, que veio a ser sua congregação. Seus pais, que se conheceram quando cantavam no coral da igreja, incentivavam a música em sua família. O rádio, bem como o coral familiar, eram meios de experienciar a música. Já como religiosa professa, licenciou-se em Pedagogia e cursou o bacharelado em Música - Piano. Após sua graduação, seguiu os estudos musicais com professores particulares. 
Concomitantemente à sua formação acadêmica em música, começou "a participar dos cursos de liturgia e canto pastoral que floresciam, por todo o Brasil, após o Concilio Vaticano II". Esses cursos "começaram no Rio de Janeiro, com o Padre Amaro, José Alves, Frei Joel e outros, no final da década de 60. Depois, logo se espalharam pelo Brasil: Recife, São Paulo, Porto Alegre, Belo Horizonte." Ela relembra que "eram quinze dias de curso, apresentando novo repertório de cantos litúrgicos, aprofundando o canto gregoriano, teoria musical, regência e composição [...]" (Lorenzetti, 2019, p. 120). Irmã Míria permaneceu de 1983 a 1985 na Alemanha e na Áustria, aprofundando seus conhecimentos em música.

Foi na cidade de Santos, em São Paulo, que Irmã Míria começou a participar do canto na igreja, inclusive orientando os ministros do canto e compondo suas primeiras missas. Ela fazia parte da Comissão de Liturgia e Música Sacra de Santos.

Foi também professora e regeu um coro infantil em uma escola. Sua ação formativa desenvolveu-se, especialmente, nos Encontros de Liturgia e Canto Pastoral e através de gravações e de materiais escritos e em partitura.

No entendimento de Irmã Míria, seu papel como formadora realiza-se através do comunicar ao outro sua "experiência de vida". Para ela, existem diferentes maneiras de ser formadora e suas canções, juntamente com suas histórias e experiências, são elementos que ajudam no processo formativo. Ao ser questionada sobre "o que é ser formadora", ela responde:

Bem, existe uma formação formal, acadêmica, de aprendizagem teórica. Mas há aquela do contato direto com o povo, do testemunho, da convivência, da experiência de vida, que se vai comunicando ao outro na relação espontânea, no convívio fraterno, no encontro informal... No meu caso, é mais a experiência de vida, o contato direto com o povo, as orientações e partilhas, algo que acontece no concreto da vida, na celebração litúrgica... As músicas que componho, minhas histórias de vida e experiências de Deus, partilhadas com o povo, são alguns elementos que ajudam no processo (Entrevista - Irmã Míria Kolling, 23/04/16) (Lorenzetti, 2019, p. 124).

Irmã Míria faleceu aos 77 anos, em 5 de maio de 2017.

\section{Padre Ney Brasil Pereira}

Padre Ney Brasil Pereira, ainda criança em São Francisco do Sul, no estado de Santa Catarina, já gostava de cantar e ouvir, pelas ruas, o som do piano sendo tocado em alguma casa (Pereira, 2006). Depois se mudou para Florianópolis e foi na catedral de lá que Padre Ney Brasil começou a cantar solos. Ao ingressar no seminário, por volta dos 12 anos, começou a aprender harmônio. Segundo Padre Ney, naquele tempo os seminários menores eram escolas de música. Foi ordenado presbítero em Roma. Ao retornar ao Brasil, obteve uma bolsa para estudar música nos Estados Unidos. 
Padre Ney Brasil, um dos mais antigos participantes dos Cursos de Canto Pastoral, fez parte da equipe de formadores. Foram cerca de 70 anos "compondo e regendo, lidando assim com formação musical” (Lorenzetti, 2019, p. 146).

Em sua ação formativa destacam-se as aulas no seminário, a regência de corais e a criação de composições e arranjos. Desde 1973, regeu o Coral Santa Cecília da catedral metropolitana de Florianópolis. Usou seu conhecimento de escrita acadêmica para realizar resenhas sobre livros de música litúrgica, assim os divulgando. Padre Ney faleceu aos 86 anos, no dia 4 de janeiro de 2017.

\section{Irmã Custódia Maria Cardoso}

Irmã Custódia Maria Cardoso teve suas primeiras experiências com música em sua familia e em um coral da igreja. Sua família toda cantava junto com o "coralzinho da capela". Sua mãe era professora na escola onde estudava. Lá também vivenciou a música.

Adolescente, ao entrar para a Congregação das Irmãzinhas da Imaculada Conceição, começou a estudar piano. Graduou-se em Música pela Universidade Sagrado Coração de Bauru, em São Paulo. Irmã Custódia busca reservar tempo para participar de congressos, pois sente a necessidade de não deixar sua formação de lado.

Irmã Custódia Cardoso, que, em 1962, começara a participar dos Cursos de Canto Pastoral, passou a ministrar cursos. Foi professora de música em escolas e organizou um coral infantil. Foi especialmente através do Coral Palestrina, dos Pequenos Cantores de Apucarana, da assessoria a cursos e das participações em rádio e televisão que Irmã Custódia firmou sua ação formativa. Permaneceu por diversos anos como assessora do Regional Sul II da CNBB. Ela conta de seu ardor e que foi assessora por 28 anos dos bispos do Paraná, sendo, desses, 15 anos de música:

[...] nas assembleias a gente sempre tem esse ardor missionário. E eu quero dar continuidade. Eu tenho esse anseio de coisas novas, de uma igreja viva. De um "negócio" que todo mundo seja feliz, que a congregação seja uma congregação que sirva para um mundo melhor e não seja um gueto como algumas são [...]. (Entrevista Irmã Custódia Cardoso, 15/11/16) (Lorenzetti, 2019, p. 157).

Irmã Custódia segue dedicando-se aos cursos e está envolvida com a formação litúrgico-musical através dos meios de comunicação, apresentando o programa Celebrar Bem, na TV Aparecida. ${ }^{6}$

6 Ver Celebrar... (2020). 


\section{CRUZAMENTOS DE QUATRO VIDAS NAS ROTAS FORMATIVAS}

Uma das preocupações da sociologia do cotidiano, segundo Pais (2003, p. 34), é procurar contínuos nos descontínuos que percorre. Os contínuos da formação musical, na Igreja Católica, podem ser vistos na permanência da ação formativa. O que parecem ser ações individuais revela uma rede complexa de cursos, de pessoas conhecidas, de continuidade através dos anos. Irmã Míria conta serem "mais de 45 anos de composição e serviço à música litúrgica".

Um acontecimento sobressai como um dos elos entre os quatro religiosos e aquilo que realizaram: o Concílio Vaticano II. Foi devido às mudanças conciliares, especialmente às pertinentes à visão de música litúrgica que foi sendo desenvolvida no Brasil, que suas rotas formativas se cruzaram.

Os espaços de formação nos quais eles tiveram experiências musicais aproximam-se: seminários, casas religiosas, cursos de canto pastoral, encontros da CNBB. Os quatro religiosos, visualizados, na tese, em capitulos separados, conheciam-se e relacionavam-se. Foi possivel "tecer" as relações entre eles através de suas falas, de fotos, de encartes de CDs, de livros.

Compreender o material empírico da tese exigiu prestar atenção às tramas que são constituídas pelas tessituras do tempo (Pais, 2016). Formar-se e participar no processo formativo de outros é algo que revela uma textura complexa, pois não há somente linearidades. As rotas não são previsiveis e constituem-se de rupturas. Implicam um olhar para o presente, o passado e o futuro, o que justifica a opção feita, de olhar para as histórias de formação e para as histórias de formadores.

Compartilho da compreensão de Pais (2003, p. 83), que explica que analisar criticamente o cotidiano "implica uma perspectiva histórica". Olhar para o cotidiano "não se esgota nas presenças imediatas" e "abarca fenômenos não presentes aqui e agora" (Pais, 2003, p. 86).

Sugiro que as concepções teológicas que os religiosos vivem impactam o modo de fazer música e ensinar, devido também à dimensão de tempo e espaço. O passado é por eles compreendido como algo que não pode ser jogado fora. É um espaço/tempo que se configura como fonte de aprendizagem. Não entendem a morte como uma barreira que encerra a ideia de fazer a música, pois a vida presente é tida como o ensaio para o que se cantará no céu, na expressão de Irmã Míria: "Ensaiando na terra o celebrar perfeito do céu, onde cantaremos o eterno louvor" (Lorenzetti, 2019, p. 141). Percebe-se que, com essa ideia, é admitido que a aprendizagem ocorre em qualquer momento da vida. A idade não se constitui em impedimento nem para aprender, nem para ensinar, pois as ações não são se encerram com o fim da vida.

A formação musical, nesse contexto religioso, é vista como algo que exige compromisso, ao mesmo tempo que proporciona o conhecimento. Ela se realiza na junção entre prática e teoria. A formação musical pode ser compreendida como significante de uma prática pedagógica não "formalizada", porém plena de escolhas pedagógicas e apresentando certa sistematização. O conceito de formação, segundo os colaboradores, aparece associado à prática que 
eles desenvolvem nos encontros. A ideia predominante é que, mesmo disponibilizando material, seja trabalhado, em um momento pontual, algo mais teórico, sem deixar faltar a prática, a vivência. Padre Weber, ao comentar sobre os cursos de salmo, conta que oferece "o subsídio e mostra a maneira de fazer".

Há busca de alternativas conceituais para retratar as situações de ensino e aprendizagem, não sendo frequentes termos como: aulas, ensino, educação, professor. Outros conceitos ganham espaço, como: formação, formador, encontros, partilhas, orientações, dicas. O papel das trocas na aprendizagem é ressaltado, sendo a experiência de vida importante no processo de formação.

Um dos momentos em que se desenvolve a formação é nos cursos ou encontros de canto litúrgico pastoral. Os cursos de canto pastoral iniciaram no final da década de 1960, no Brasil, sob coordenação do Cônego José Amaro Cavalcanti de Albuquerque ${ }^{7}$ e visavam à animação e formação teórica e prática de compositores de música litúrgica. Diversos nomes são adotados para designar tais momentos e espaços que continuam a ocorrer na Igreja. Cada um dos entrevistados revelou especificidades em seu modo de conduzi-los, com utilização de estratégias variadas para transmitir o conhecimento: ensaios, brincadeiras, histórias, experiências, repetição, instrumentistas tocando o próprio instrumento.

O "formador" é aquele que assessora cursos, publica materiais, produz o conhecimento. Ele assume intensa relevância no contexto religioso e um de seus papéis é mostrar as maneiras de fazer. Segundo Padre Weber, o formador é aquele que "se formou bem e que agora está disponivel para repartir com os outros o que sabe" (Lorenzetti, 2019, p. 196). Ele considera formadora "toda pessoa que tem uma certa formação", ministra cursos e deixa alguma marca. A expressão "deixar marcas" é utilizada em sua relação com a história de alguém que, tendo vivido muitas experiências, deixará um legado para o futuro. Padre Weber ressalta que aquilo que aprendeu quer "passar para frente para não ficar parado" e espera que "alguém depois assuma e leve em frente [...] como contribuição para a Igreja também". O formador, muitas vezes, aparece quase como um sinônimo de professor, compartilhando conhecimento e experiências no contexto litúrgico-musical. Para Padre Ney, o formador tem a responsabilidade de "transmitir não apenas teoria, mas vivência” (Lorenzetti, 2019, p. 146).

No trabalho, a ideia de "comunidade" é recorrente, por vezes como sinônimo de assembleia, povo, igreja de gente, base. Entre seus objetivos, a formação tem uma finalidade comunitária, como explicitado por Irmã Custódia que, ao formar, preocupa-se não só em fazer um cantor cantar, mas em "fazê-lo feliz com a missão que ele está realizando em benefício da comunidade"

\footnotetext{
7 Monsenhor Amaro Cavalcanti de Albuquerque Filho (1928-2001), coordenou a Comissão Arquidiocesana de Música Sacra do Rio de Janeiro, foi professor e deu cursos de orientação musical e litúrgica em várias dioceses do Brasil.
} 
(Lorenzetti, 2019, p. 166). A palavra comunidade articula-se a outras expressões como missão, ministério, serviço, dom.

O significado de dom torna-se relevante, quando se considera que as pessoas assumem "seus dons" e que com eles servem "à comunidade" nas palavras de Irmã Custódia. O músico litúrgico, incluindo o que desempenha o papel de formador, é visto por Irmã Míria como alguém com "dom especial" devido à sua função específica que "exige longa formação". Irmã Míria compreende tal formação como um "processo contínuo e sempre inacabado", pois um músico não se improvisa. O longo tempo requerido para a preparação de um músico com habilidades especificas para atuar na Igreja Católica impacta o modo de olhar para aqueles que possuem formação específica, os quais são diferenciados por meio de expressões como talento, dom, inspiração.

Padre Weber compreende o "dom" como inato, o qual, no entanto, requer estudo para ser exercitado. Em quase todas as falas dos entrevistados, a ideia de dom aparece como algo preexistente, mas que precisa ser desenvolvido através do estudo, através da busca de conhecimentos técnico-musicais. Eles não deixam de considerar os aspectos sociais para o desenvolvimento do que chamam de dom. Irmã Míria explica que "depende muito das oportunidades, da família, da escola e também da própria pessoa". Irmã Custódia revela a necessidade de ter condições financeiras para estudar música, bem como o apoio dos pais.

O conceito de dom necessita de um olhar crítico a partir da perspectiva da educação musical, pois pode ditar regras relativas a quem pode ou não aprender. $\mathrm{Na}$ tese houve a preocupação em entender os sentidos empregados ao utilizar esse conceito. O termo é polissêmico e, por vezes, é utilizado como referência a um retorno dado a uma comunidade através da experiência musical. A visão apresentada por autores como Elias (1995) distingue os diversos fatores envolvidos no aprender música, ajudando a desmistificar a figura do "gênio" e a ideia de dom.

\section{CONSIDERAÇÕES FINAIS}

Neste artigo apresentei algumas análises feitas a partir da tese de doutorado defendida em 2019, que teve como objetivo compreender as rotas formativas de quatro religiosos católicos. A pesquisa apontou que há especificidades na música feita no contexto religioso, estando os conteúdos musicais atrelados a particularidades de crença religiosa, visões de sociedade e questões rituais litúrgicas. A inseparabilidade entre música e liturgia manifesta-se no modo como se repassa o conhecimento nos encontros, em que as questões técnico-musicais são desenvolvidas juntamente com o modo de executar, o sentido do texto, a função ritual. Simultaneamente à apresentação do repertório, busca-se despertar e fortalecer a fé.

As rotas formativas dos quatro religiosos foram apresentadas, mostrando as possibilidades de formar-se nesse contexto. As ações formativas, que inicialmente pareciam individuais, revelaram uma rede complexa de cursos, de pessoas conhecidas, de continuidade através dos anos. A formação musi- 
cal na tese foi compreendida como uma prática educativa plena de escolhas pedagógicas, que apresenta certas sistematizações, porém não na lógica da continuidade de um curso regular de música. As formações são oferecidas a partir de encontros e outros momentos, o que faz com que aspectos de socialização ganhem muita força na compreensão de como se dá a aprendizagem musical. Há busca de alternativas conceituais para retratar as situações de ensino e aprendizagem, ganhando espaço conceitos como: formação, formador, encontros, partilhas, orientações, dicas. O papel das trocas na aprendizagem é ressaltado, sendo a experiência de vida importante no processo de formação.

\section{REFERENCIAS}

ALMEIDA, Márcio Antônio. Música brasileira na liturgia: obra, contexto e produto. 2014. Tese (Doutorado em Música) - Instituto de Artes, Universidade Estadual Paulista, São Paulo, 2014.

BURKE, Peter. Testemunha ocular: o uso de imagens como evidência histórica. Traduzido por Vera Maria Xavier dos Santos. São Paulo: Editora Unesp, 2017.

CATTELAN, Lucas. Diários de um músico e professor. experiências na Catedral Metropolitana de Santa Maria - RS. 2012. Monografia (Licenciatura Plena em Música) - Centro de Artes e Letras, Universidade Federal de Santa Maria, Santa Maria, 2012.

"CELEBRAR Bem" estreia neste sábado na TV Aparecida!. A12, [s. l.], 31 jul. 2020. Disponivel em: https://www.a12.com/tv/programas/celebrar-bem/ celebrar-bem-estreia-neste-sabado-na-tv-aparecida. Acesso em: 20 ago. 2020.

DIAS, José Sérgio. Reflexões sobre experiências de autoaprendizagem musical na Paróquia São Judas Tadeu. 2017. Monografia (Licenciatura em Música) - Faculdade Santa Marcelina, São Paulo, 2017.

ELIAS, Norbert. Mozart: sociologia de um gênio. Organizado por Michael Schröter. Tradução Sérgio Goes de Paula. Revisão técnica Renato Janine Ribeiro. Rio de Janeiro: Zahar, 1995.

FONSECA, Joaquim. Panorama da música litúrgica no Brasil. In: MOLINARI, Paula (org.). Música brasileira na liturgia II. São Paulo: Paulus, 2009. p. 27-34. (Coleção Liturgia e Música, n. 8).

FONSECA, Joaquim; WEBER, José. A música litúrgica no Brasil 50 anos depois do Concílio Vaticano II. São Paulo: Paulus, 2015. (Coleção Marco Conciliar). 
INSTITUTO BRASILEIRO DE GEOGRAFIA E ESTATÍSTICA. Censo 2010: número de católicos cai e aumenta o de evangélicos, espíritas e sem religião. Agência IBGE Noticias, [s. l.], 26 jun. 2012. Disponivel em: https:// agenciadenoticias.ibge.gov.br/agencia-sala-de-imprensa/2013-agenciade-noticias / releases / 14244-asi-censo-2010-numero-de-catolicos-cai-eaumenta-o-de-evangelicos-espiritas-e-sem-religiao. Acesso em: 20 ago. 2020.

JEFREMOVAS, Pietra. Ser professor de piano: dois casos de atuação dentro da Igreja Católica em Canoas/RS. 2017. Trabalho de Conclusão de Curso (Licenciatura em Música) - Instituto de Artes, Universidade Federal do Rio Grande do Sul, Porto Alegre, 2017.

JOHANSEN, Geir. Musikdidatik and Sociolgy. In: WRIGHT, Ruth. Sociology and music education. New York: Ashgate Book: Routledge, 2010. p. 207-221.

KERTZ-WELZEL, Alexandra. Revisiting Bildung and its meaning for international music education policy. In: SCHMIDT, Patrick; COLWELL, Richard. Policy and the political life of music education. New York: Oxford University Press, 2017. p. 107-120.

LORENZETTI, Michelle Arype Girardi. Educação musical na Igreja Católica: reflexões sobre experiências em contextos da Grande Porto Alegre/RS. 2012. Trabalho de Conclusão de Curso (Licenciatura em Música) - Instituto de Artes, Universidade Federal do Rio Grande do Sul, Porto Alegre, 2012.

Aprender e ensinar música na Igreja Católica: um estudo de caso em Porto Alegre/RS. 2015. Dissertação (Mestrado em Música) - Instituto de Artes, Universidade Federal do Rio Grande do Sul, Porto Alegre, 2015.

Formar-se e ser formador: rotas formativas musicais de religiosos no contexto católico brasileiro na perspectiva da sociologia da educação musical e da vida cotidiana. 2019. Tese (Doutorado em Música) - Instituto de Artes, Universidade Federal do Rio Grande do Sul, Porto Alegre, 2019. Disponivel em: http://hdl.handle.net/10183/193128. Acesso em: 20 ago. 2020.

LOURO, Ana Lúcia; RECK, André Müller; OLIVEIRA, Fernanda de Assis; ZACARIAS, Luis Felipe Camargo. Olhando para aprendizagens informais em música: algumas experiências junto a movimentos da Igreja Católica. In: ENCONTRO REGIONAL SUL DA ABEM, 14., 2011, Maringá. Anais [...]. Maringá: Abem, 2011. p. 215-224.

MAFRA, Clara. Números e narrativas. Debates do NER, Porto Alegre, n. 24, p. 13-25, jul./ dez. 2013.

MOLINARI, Paula (org.). Música brasileira na liturgia II. São Paulo: Paulus, 2009. (Coleção Liturgia e Música, n. 8). 
NOGUEIRA, Ana Greice Alves Teixeira. Práticas de canto em grupo em uma comunidade religiosa de Anápolis. 2012. Monografia (Licenciatura em Música à Distância) - Universidade de Brasília, Brasília, 2012.

OLIVEIRA NETO, Fernando Martins de. Música e religiosidade: um estudo sobre a transmissão musical na Comunidade Católica Shalom - Missão Natal/RN. 2017. Dissertação (Mestrado em Música) - Escola de Música, Universidade Federal do Rio Grande do Norte, Natal, 2017.

PAIS, José Machado. Nas rotas do quotidiano. Revista Crítica de Ciências Sociais, [s. l.], n. 37, p. 105-115, jun. 1993.

Vida cotidiana: enigmas e revelações. São Paulo: Cortez, 2003.

Tessituras do tempo na contemporaneidade. ArtCultura, Uberlândia, v. 18, n. 33, p. 7-18, jul./dez. 2016.

PEREIRA Ney Brasil. [Entrevista em fevereiro de 2006, por ocasião do seu Jubileu de Ouro Presbiteral, ao] Pe. José Artulino Besen. Encontros Teológicos n. 43, Florianópolis, ano 21, n. 1, p. 121-143, 2006.

SANTOS, Regina Marcia Simão; FIGUEIREDO, Theógenes Eugênio. "Ia porque tocava. Tocava porque ia." - o ambiente de ensino aprendizagem como fator de sentido: depoimento dos que lidam com música eclesiástica. In: ENCONTRO ANUAL DA ASSOCIAÇÃO BRASILEIRA DE EDUCAÇÃO MUSICAL, 12., 2003, Florianópolis. Anais [...]. Florianópolis: Abem, 2003. p. $722-728$.

SOUZA, Jusamara. Contribuições teóricas e metodológicas da sociologia para a pesquisa em educação musical. In: ENCONTRO ANUAL ABEM, 5.; SIMPÓSIO PARANAENSE DE EDUCAÇÃO MUSICAL, 5., 1996, Londrina. Anais [...]. Londrina: Abem, 1996. p. 11-40.

(org.). Música, cotidiano e educação. Porto Alegre: Programa de PósGraduação em Música do Instituto de Artes da UFRGS, 2000.

Pensar a educação musical como ciência: a participação da Abem na construção da área. Revista da Abem, Porto Alegre, v. 16, p. 25-30, mar. 2007.

Música, educação e vida cotidiana: apontamentos de uma sociografia musical. Educar em Revista, Curitiba, n. 53, p. 91-111. jul./set. 2014.

STAKE, Robert E. Investigación con estudio de casos. Madrid: Morata, 1999.

TEIXEIRA, Faustino. Faces do catolicismo brasileiro contemporâneo. Revista USP, São Paulo, n. 67, p. 14-23, set./nov. 2005. 
TORRES, Maria Cecília de Araújo Rodrigues. Entrelaçamentos de lembranças musicais e religiosidade: "quando soube que cantar era rezar duas vezes...”. Revista da Abem, Porto Alegre, v. 11, p. 63-68, set. 2004.

UNIVERSA LAUS: documento I. Tradução: Vinícius Mariano de Carvalho. In: FONSECA, Joaquim. Quem canta? O que cantar na liturgia?. São Paulo: Paulus, 2008. p. 77-88. (Coleção Liturgia e Música). 
Michelle Arype Girardi Lorenzetti é doutora em Música (Educação Musical) pela Universidade Federal do Rio Grande do Sul (UFRGS). Realizou seu estágio de doutorado sanduíche pelo Programa de Doutorado Sanduíche no Exterior (PDSE - Capes) no Institut für Musikpädagogische Forschung da Hochschule für Musik Theater und Medien Hannover (Instituto de Pesquisa em Educação Musical da Escola Superior de Música, Teatro e Mídias de Hanôver, Alemanha) sob supervisão do Dr. Andreas Lehmann-Wermser. É mestra em Música (Educação Musical), bacharel (Habilitação Canto) e possui Licenciatura em Música pela UFRGS. É especialista em Música Ritual pelo Centro Universitário Campo Limpo Paulista (SP). É membro do grupo de pesquisa Educação Musical e Cotidiano (EMCO/UFRGS) sob liderança da Dra. Jusamara Souza. De 2018 a 2019 atuou como professora substituta no Instituto Federal Rio Grande do Sul (IFRS) - Campus Porto Alegre. Atua como professora na pós-graduação lato sensu no Centro Universitário Salesiano de São Paulo. É pós-doutoranda na UFRGS. https://orcid.org/0000-0001-5613-8058 